\title{
Proceeding
}

Supplementary Issue: Winter Conferences of Sports Science. Costa Blanca Sports Science Events, 22-23 March 2021. Alicante, Spain.

\section{Effects of traditional training compared to functional training in metabolic age and visceral fat in 18-30 old subjects}

\author{
ANDIS BOGDANI ${ }^{1}$, GENTI PANO 2 \\ ${ }^{1}$ Department of Movement and Health, Faculty of Physical Activity and Recreation, Sports University of \\ Tirana, Tirana, Albania \\ ${ }^{2}$ Department of Kinesiology, Faculty of Rehabilitation Sciences, Sports University of Tirana, Tirana, Albania
}

\begin{abstract}
Over the last several years, increasing attention has been paid to abdominal adiposity and its association with increased mortality (Janssen I et al., 2004; Pischon T et al., 2008). Evidence for the positive effect of exercise on novel risk factors of the metabolic syndrome such as disturbances in adipokine secretion and low-grade inflammation confirms the importance of exercise in the treatment of the 'new concept' metabolic syndrome (You T, Nicklas BJ., 2008). Main objective of this paper was to compare the effects of traditional training and functional training on metabolic age and visceral fat in 18-30 years old subjects. 40 subjects: 20 in traditional training group (12 Males and 6 Females) \& 20 in functional training group (12 Males and 6 Females), 18-30 years old were selected to take part in this 14-weeks intervention study. Subject underwent body composition parameters including visceral fat and metabolic age using BIA (Tanita BC 601). Data results pointed out that both training regimens produced a significant reduction $(p<.05)$ in metabolic age and visceral fat but the subjects in the functional training group had better results.
\end{abstract}

Keywords: Functional training; Traditional training; Body composition; Low back pain.

Cite this article as:

Bogdani, A., \& Pano, G.(2021). Effects of traditional training compared to functional training in metabolic age and visceral fat in 18-30 old subjects. Journal of Human Sport and Exercise, 16(3proc), S1402-S1410. https://doi.org/10.14198/jhse.2021.16.Proc3.56

Corresponding author. Department of Kinesiology, Faculty of Rehabilitation Sciences, Sports University of Tirana, Tirana, Albania.

E-mail: g.pano@ust.edu.al

Abstract submitted to: Winter Conferences of Sports Science. Costa Blanca Sports Science Events, 22-23 March 2021. Alicante, Spain.

JOURNAL OF HUMAN SPORT \& EXERCISE ISSN 1988-5202.

(c) Faculty of Education. University of Alicante.

doi:10.14198/jhse.2021.16.Proc3.56 


\section{INTRODUCTION}

The metabolic syndrome is a complex clustering of cardiometabolic abnormalities associated with aging, physical inactivity, and abdominal adiposity (Carr DB et al., 2004; Facchini FS et al., 2001; Grundy SM et al., 2004). Of the risk factors used to identify the metabolic syndrome, elevated abdominal visceral fat (AVF) has consistently been shown to be associated with increased cardiometabolic risk (Nicklas BJ et al., 2004). Over the last several years, increasing attention has been paid to abdominal adiposity and its association with increased mortality (Janssen I et al., 2004; Pischon T et al., 2008). Visceral adipose tissue seems to be the most pathogenic fat depot and is considered to play a central role in the metabolic syndrome.

Adipose tissue is not only considered an energy storage organ but is now recognized as an endocrine and paracrine organ that plays an active role in energy homeostasis through the release of a large number of cytokines and bioactive mediators (Ahima RS., 2006). These novel risk factors and markers can not only influence body weight homeostasis but also insulin resistance, diabetes, lipid metabolism, inflammation, explaining premature atherosclerosis in obesity (Van Gaal LF et al., 2006). In contrast with the accumulation of peripheral subcutaneous fat, excessive fat accumulation in the abdominal viscera is strongly associated with obesity-related complications, including type 2 diabetes and cardiovascular disease (Nicklas B.J et al., 2004). The health crisis resulting from the adiposity that appears at these specific anatomical locations has been termed "metabolic obesity" (Hamdy $O$ et al., 2006).

Among the different indicators of obesity, the percentage of fat, fat mass and waist circumference are the most commonly studied measures, the latter being the most relevant to indicate cardiometabolic problems (Barazzoni R et al., 2019; Goh LGH et al., 2014) and with the strongest relationship with visceral fat (Heydari $M$ et al., 2012) The percentage of fat distinguishes fat from lean body mass and is a better obesity indicator when compared to the total weight and BMI, resulting in a more consistent diagnosis (Glaner MF., 2005). Exercise training provides an economically viable, non-pharmacological approach for eliciting beneficial adaptations in body composition and cardiometabolic risk. Only a limited number of exercise interventions have systematically examined the impact of endurance training intensity on fat loss and in particular AVF loss under equivalent energy expenditures (Slentz CA et al., 2004; Slentz CA et al., 2005). Evidence for the positive effect of exercise on novel risk factors of the metabolic syndrome such as disturbances in adipokine secretion and low-grade inflammation confirms the importance of exercise in the treatment of the "new concept' metabolic syndrome (You T, Nicklas BJ., 2008). The effective elimination of excessive abdominal fat in obese people through lifestyle modification and adjuvant appetite suppressants have been associated with reductions in fasting plasma glucose, triglycerides, and HOMA score (Hong H et al., 2014). There is robust evidence that high-volume, moderate intensity continuous training (MICT) with exercise sessions $\geq$ 45 min can reduce abdominal visceral fat (Hong $\mathrm{H}$ et al., 2014; Ross $\mathrm{R}$ et al., 2000; Irwin M. L et al., 2010; Miyamoto-Mikami E et al., 2015) as well as improve body composition, cardiovascular fitness, and other health-related parameters including insulin sensitivity and lipid profile in both healthy and obese people (McInnis K. J et al., 2003; Donnelly J. E et al., 2009). The facilitation effects of high-intensity exercise, in comparison to low-intensity exercise, on abdominal visceral fat reduction have been demonstrated in obese women participated in endurance exercise training and was partly attributed to the greater negative energy balance, and the potential increase in lipolytic hormone secretion (Irving et al., 2008). Specifically, the lipolytic hormone of catecholamines promote lipolysis through b3-adrenoceptors, which are more common in abdominal fat than in subcutaneous fat (Ibrahim., 2010). 


\section{Objectives}

Main objective of this paper was to evaluate the effects of traditional and functional training in metabolic age and visceral fat in young subjects.

\section{METHODOLOGY}

A total of 40 subjects; 20 in traditional training group (12 Males and 6 Females)) \& 20 in functional training group (12 Males and 6 Females), 18-30 years old were selected to take part in this 14-week intervention study. Subject underwent body composition parameters including visceral fat and metabolic age using BIA (Tanita BC 601). Traditional exercise training program (control group) consisted in: $3 \mathrm{x}$ week frequencies; 2 3 major muscles groups per session (60 min session including 10 min warm-up and cool down). On the other side functional exercises training program consisted in: $3 x$ week frequencies including; General functional training exercises (60 min session including $10 \mathrm{~min}$ warm-up and cool down). Statistical analyses were conducted using MedCalc 19.8 statistical software. The analysis of pre and post visceral fat scale (1 to 12) were carried out by comparing means of experimental and control groups. ANOVA analysis with two repeated measurements (pre and post) was used to identify and statistically evaluate a possible change as a training effect.

\section{Sample exercises of the traditional training program (3 days / week)}

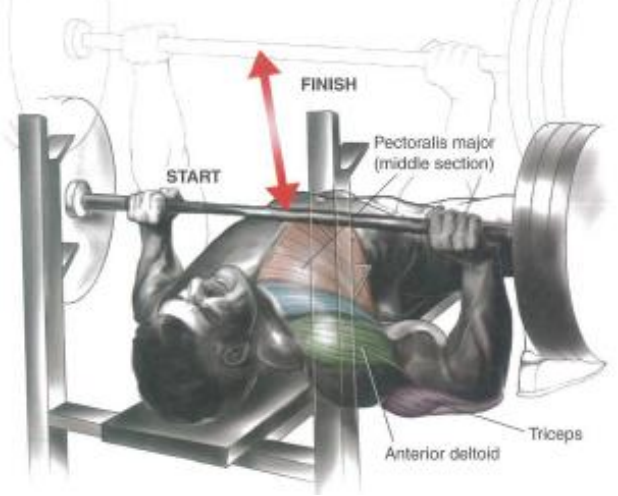

Figure 1. Bench press. 4 sets me 10, 8, 6, 6 reps.

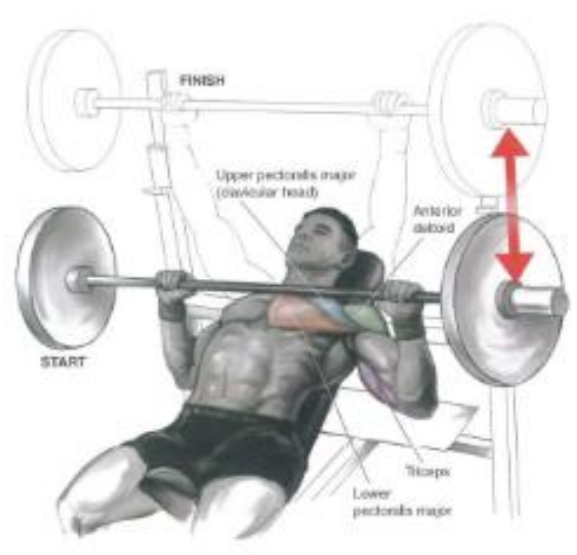

Figure 2. Incline press. 3 sets me 8, 6, 6 reps. 


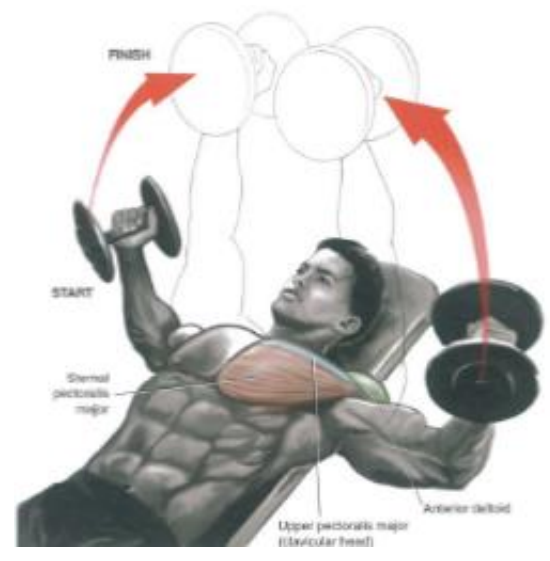

Figure 3. Dumbbell fly. 3 sets me 10, 8, 6, reps.

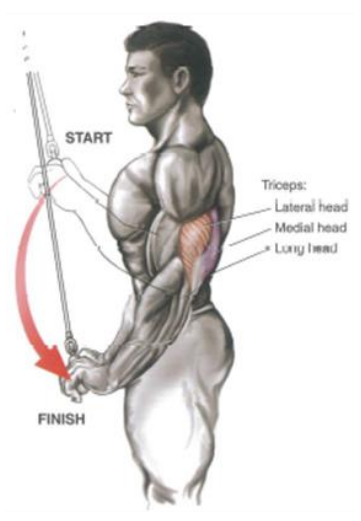

Figure 4. Pull-downs. 3 sets 10, 8, 6 reps.

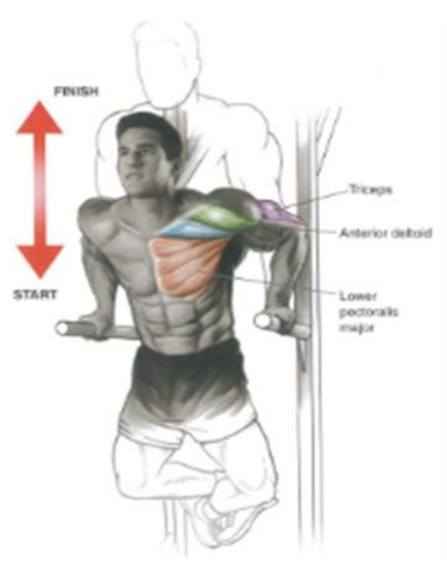

Figure 5. Weighted dips. 3 sets 10, 8, 6 reps. 


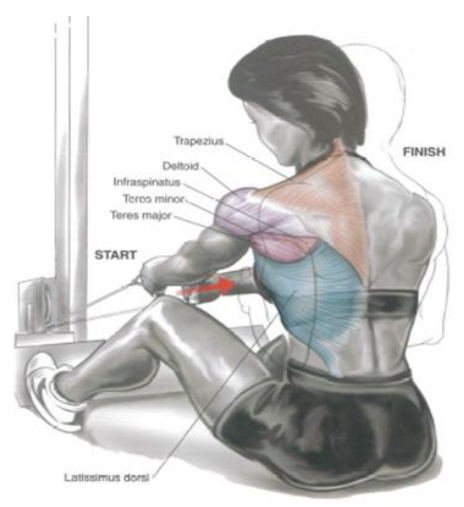

Figure 6. Seated cable rows. 3 sets 10, 8, 6 reps.

\section{Sample exercises of the functional training program (3 days / week)}

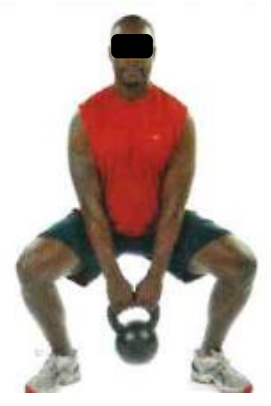

Figure 7. Sumo squat. 3 sets 15 reps.

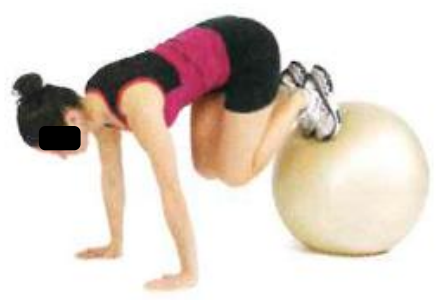

Figure 8. Reverse fit ball crunch. 3 sets 10-15 reps.

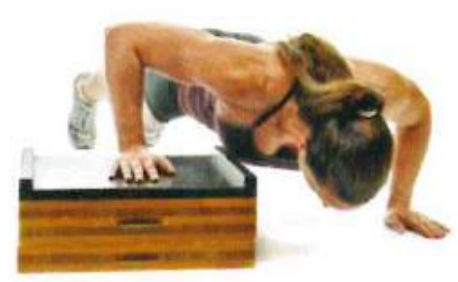

Figure 9. Modified push-up. 3 sets 10-12 reps. 
Data results pointed out that both training regimens produced a significant reduction $(p<.05)$ in; Metabolic age and Visceral fat, both in males and females' subjects. Also, data results show that in the functional training group the results were more positive suggesting that regarding metabolic age and visceral fat functional training exercises if are properly combined can be effective in 18-30 years age category. Descriptive Statistics results are presented in the tables below (see Table 1, Table 2).

Table 1. Descriptive statistics for control group.

\section{Traditional training}

\begin{tabular}{lcccccccc}
\hline & N & Age & Weight & Height & BMI & \% Fat of Whole Body & Muscle mass & Visceral fat \\
\hline Pre & 20 & 27 & 73 & 168.2 & 25.8 & 31 & 50 & 6.3 \\
Post & 20 & 27 & 69 & 168.2 & 24.4 & 26 & 53.5 & 4.5 \\
\hline
\end{tabular}

Table 2. Descriptive statistics for experimental group.

\begin{tabular}{ccccccccc} 
& \multicolumn{8}{c}{ Functional training } \\
\hline & N & Age & Weight & Weight & BMI & \% Fat of Whole Body & Muscle mass & Visceral fat \\
\hline Pre & 20 & 25.5 & 76 & 172 & 25.77 & 29 & 52 & 6.5 \\
Post & 20 & 25.5 & 56.8 & 172 & 23.2 & 24 & 56 & 3.5 \\
\hline
\end{tabular}

Visceral fat plot means clustered by groups (Group No.1: Traditional training, Group No.2: Functional training) is presented in Figure 10.

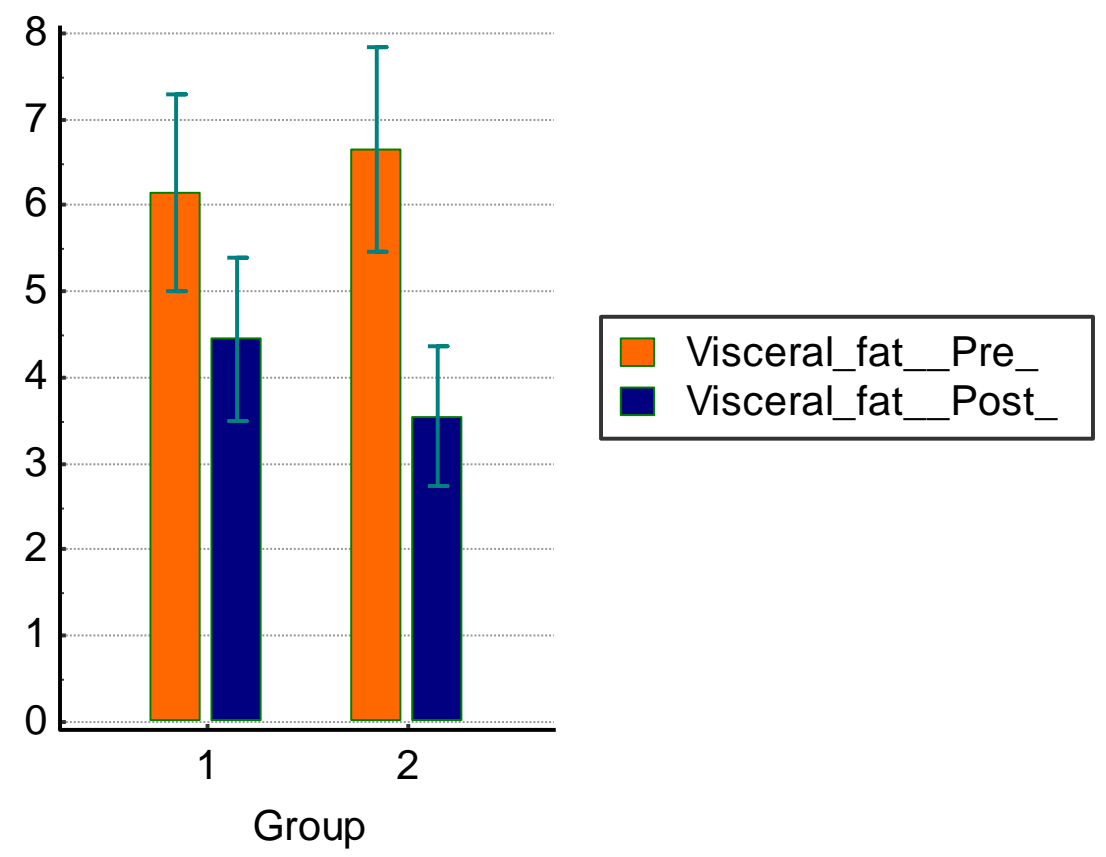

Figure 10. Visceral fat plot means clustered by groups (Group No.1: Traditional training, Group No.2: Functional training)

Pre and post measurements were analysed to evaluate visceral fat improvements. ANOVA with two repeated measures results were used in order to reveal a possible significant group effect for visceral fat differences between functional training and traditional training group. There was a statistically significant effect of 
intervention on visceral fat between groups, $F(2,38)=11.28, p=.002$. The two Repeated Measures ANOVA results revealed a significant difference between pre and post measures in visceral fat $(p<.05)$. The two Repeated Measures ANOVA results revealed a non-significant effect of intervention on visceral fat between males and females $(p>.05)$. Results concluded that functional training programme had a statistically significant effect on visceral fat. $(p<.05)$.

\section{DISCUSSION AND CONCLUSIONS}

Both exercise training regimens successfully produced a reduction in visceral fat which suggest that both training methods may be an effective component for inducing changes also in body composition. More specifically functional training reduced body weight, BMI, \% body fat, fat mass and waist circumference in all participants. Individualized training load, total exercise training time, may further optimize the time-efficiency advantage of both functional and traditional training regimens in visceral and body fat changes in both males and females. The two Repeated Measures ANOVA results revealed a significant difference in visceral fat between control and experimental groups concluding that functional training programme had a statistically significant effect on visceral fat. $(p<.05)$. Further studies with larger groups can better examine the relationship between training type, training volume and training intensity in visceral fat and in body composition changes considering body phenotype and nutritional protocol.

\section{REFERENCES}

Ahima RS (2006) Adipose tissue as an endocrine organ. Obesity (Silver Spring) 14 Suppl 5: 242S-249S. https://doi.org/10.1038/oby.2006.317

Barazzoni R, Gortan Cappellari G, Semolic A, lus M, Zanetti M, Gabrielli A, et al. Central adiposity markers, plasma lipid profile and cardiometabolic risk prediction in overweight-obese individuals. Clin Nutr. 2019;38(3):1171-9. https://doi.org/10.1016/j.clnu.2018.04.014

Carr DB, Utzschneider KM, Hull RL, Kodama K, Retzlaff BM, Brunzell JD, Shofer JB, Fish BE, Knopp $\mathrm{RH}$, Kahn SE. Intra-abdominal fat is a major determinant of the National Cholesterol Education Program Adult Treatment Panel III criteria for the metabolic syndrome. Diabetes 2004;53(8):208794. [PubMed: 15277390]. https://doi.org/10.2337/diabetes.53.8.2087

Donnelly J. E, Blair S. N, Jakicic J. M, Manore M. M, Rankin J. W, and Smith B. K, "Appropriate physical activity intervention strategies for weight loss and prevention of weight regain for adults," Medicine \& Science in Sports \& Exercise, vol. 41, no. 2, pp. 459-471, 2009. https://doi.org/10.1249/MSS.0b013e3181949333

Facchini FS, Hua N, Abbasi F, Reaven GM. Insulin resistance as a predictor of age- related diseases. Journal of Clinical Endocrinology Metabolism 2001;86(8):3574-8. [PubMed: 11502781]. https://doi.org/10.1210/jcem.86.8.7763

Glaner MF. Índice de massa corporal como indicativo da gordura corporal comparado às dobras cutâneas. Rev Bras Med Esporte. 2005;11(4):243-6. https://doi.org/10.1590/S151786922005000400008

Goh LGH, Dhaliwal SS, Welborn TA, Lee AH, Della PR. Anthropometric measurements of general and central obesity and the prediction of cardiovascular disease risk in women: A cross-sectional study. BMJ Open. 2014;4(2)1-9. https://doi.org/10.1136/bmjopen-2013-004138

Grundy SM, Brewer HB Jr. Cleeman JI, Smith SC Jr. Lenfant C. Definition of metabolic syndrome: Report of the National Heart, Lung, and Blood Institute/American Heart Association conference on scientific issues related to definition. Circulation 2004;109(3):433-8. [PubMed: 14744958]. https://doi.org/10.1161/01.CIR.0000111245.75752.C6 
Hamdy O, Porramatikul S, and Al-Ozairi E, "Metabolic obesity: the paradox between visceral and subcutaneous fat," Current Diabetes Reviews, vol. 2, no. 4, pp. 367-373, 2006. https://doi.org/10.2174/1573399810602040367

Heydari M, Freund J, Boutcher SH. The effect of high-intensity intermittent exercise on body composition of overweight young males. J Obes. 2012;2012(480467)1-8. https://doi.org/10.1155/2012/480467

Hong $\mathrm{H}$, Jeong J, Kong J et al., "Effect of walking exercise on abdominal fat, insulin resistance and serum cytokines in obese women," Journal of Exercise Nutrition and Biochemistry, vol. 18, no. 3, pp. 277285, 2014. https://doi.org/10.5717/jenb.2014.18.3.277

Ibrahim, M. M. (2010). Subcutaneous and visceral adipose tissue: structural and functional differences. Obes. Rev. 11, 11-18. https://doi.org/10.1111/j.1467-789X.2009.00623.x

Irving, B. A., Davis, C. K., Brock, D. W., Weltman, J. Y., Swift, D., Barrett, E. J., et al. (2008). Effect of exercise training intensity on abdominal visceral fat and body composition. Med. Sci. Sports Exerc. 40, 1863-1872. https://doi.org/10.1249/MSS.0b013e3181801d40

Irwin M. L, Yasui Y, Ulrich C. M. et al., "Effect of exercise on total and intra-abdominal body fat in postmenopausal women: a randomized controlled trial," Journal of the American Medical Association, vol. 289, no. 3, pp. 323-330, 2003. https://doi.org/10.1001/jama.289.3.323

Janssen I, Katzmarzyk PT, Ross R (2004) Waist circumference and not body mass index explains obesity related health risk. Am J Clin Nutr 79: 379-384. https://doi.org/10.1093/ajcn/79.3.379

McInnis K. J, Franklin B. A, and Rippe J. M, "Counseling for physical activity in overweight and obese patients," American Family Physician, vol. 67, no. 6, pp. 1249-1256, 2003.

Miyamoto-Mikami E, Sato K, Kurihara T et al., "Endurance training-induced increase in circulating irisin levels is associated with reduction of abdominal visceral fat in middle-aged and older adults," PLOS ONE, vol. 10, no. 3, Article IDe0120354, 2015. https://doi.org/10.1371/journal.pone.0120354

Nicklas B. J., Penninx B. W. J. H., Cesari M. et al., "Association of visceral adipose tissue with incident myocardial infarction in older men and women: The Health, Aging and Body Composition Study," American Journal of Epidemiology, vol. 160, no. 8, pp. 741-749, 2004. https://doi.org/10.1093/aje/kwh281

Nicklas BJ, Penninx BW, Cesari M, Kritchevsky SB, Newman AB, Kanaya AM, Pahor M, Jingzhong D, Harris TB. Association of visceral adipose tissue with incident myocardial infarction in older men and women: The Health, Aging and Body Composition Study. Am J Epidemiol 2004;160(8):741-9. [PubMed: 15466496]

Pischon T, Boeing H, Hoffmann K, Bergmann M, Schulze MB, et al. (2008) General and abdominal adiposity and risk of death in Europe. $\mathrm{N}$ Engl $\mathrm{J}$ Med 359: 2105-2120. https://doi.org/10.1056/NEJMoa0801891

Ross R, Dagnone D, Jones P. J. H. et al., "Reduction in obesity and related comorbid conditions after diet-induced weight loss or exercise-induced weight loss in men. A randomized, controlled trial," Annals of Internal Medicine, vol. 133, no. 2, pp. 92-103, 2000. https://doi.org/10.7326/0003-4819133-2-200007180-00008

Slentz CA, Aiken LB, Houmard JA, Bales CW, Johnson JL, Tanner CJ, Duscha BD, Kraus WE. Inactivity, exercise, and visceral fat. STRRIDE: a randomized, controlled study of exercise intensity and amount. J Appl Physiol 2005;99(4):1613-8. [PubMed: 16002776]. https://doi.org/10.1152/japplphysiol.00124.2005

Slentz CA, Duscha BD, Johnson JL, Ketchum K, Aiken LB, Samsa GP, Houmard JA, Bales CW, Kraus WE. Effects of the amount of exercise on body weight, body composition, and measures of central obesity: STRRIDE--a randomized controlled study. Arch Intern Med 2004;164(1):31-9. [PubMed: 14718319]. https://doi.org/10.1001/archinte.164.1.31 
Van Gaal LF, Mertens IL, De Block CE (2006) Mechanisms linking obesity with cardiovascular disease. Nature 444: 875-880. https://doi.org/10.1038/nature05487

You T, Nicklas BJ (2008) Effects of exercise on adipokines and the metabolic syndrome. Curr Diab Rep 8: 7-11. https://doi.org/10.1007/s11892-008-0003-4

\section{(c) $(9)(\mathrm{F}$}

This work is licensed under a Attribution-NonCommercial-NoDerivatives 4.0 International (CC BY-NC-ND 4.0). 